\title{
Designing a Digital Educational Environment for Implementing Comprehensive Changes in the Teacher's Pedagogical Activities
}

\author{
Vladimir I. Stymkovskiy ${ }^{1 *}$, Marina G. Sergeeva ${ }^{1}$, Anna K. Oreshkina ${ }^{2}$, and Elena $V$. \\ Chernega $^{1}$ \\ ${ }^{1}$ Bauman Moscow State Technical University, 2nd Baumanskaya str., 5/1, 105005, Moscow, Russia \\ ${ }^{2}$ Russian Academy of Education, Pogodinskaya str., 8, 119121, Moscow, Russia
}

\begin{abstract}
At present, in Russia there is a contradiction between the familiar, time-tested, and innovative technologies in the field of education. It is possible to overcome this conflict by combining full-time and distance learning in the context of a digital educational environment that requires certain applied skills from an educational institution employee. Special operational systems that integrate information from related sciences may be the basis of the digital educational environment in the context of the application of information management technologies. Such systems are required to facilitate the unification, accumulation and preservation of knowledge, as well as ensuring free access to intellectual resources. The authors of the article identified four basic functions of the application of information-type technologies during the training of future representatives of a particular profession: informational and educational, formative, estimative and corrective, research. It is noted that these functions do not act separately, but as elements of a single system, depending on conditions determined by the characteristics of the information educational environment. The analysis allows the authors to argue that at this stage of the educational process evolution, the main task is to create a methodology related to the use of information management technologies in the development of educational electronic materials and their implementation in the context of pedagogical activity.
\end{abstract}

\section{Introduction}

Sociocultural factors contributing to the formation of an open information society in our country (the growing popularity of distance education, the significant role of the Internet in modern life, the implementation of an increasing number of cognitive operations in automatic mode) have led to an update in the list of requirements for a young specialist with higher professional education, ready for active interaction with society in the context of mass digitalization of education $[1,2]$.

\footnotetext{
* Corresponding author: lawyer@bmstu.ru
} 
The main engines of modern education in Russia and abroad are training in the form of electronic and distance education, online courses, the use of information technology in the educational process, etc. $[3,4,5]$. The educational, and partly the tutorial process is gradually being virtualized, which makes people's thinking more fragmentary and "file" ("screen"), increases the split that exists between the familiar, time-tested, and innovative educational technologies. The principle of interactivity contributes to overcoming this conflict, helps to find a middle ground between traditional and modern approaches to ensuring the interaction of teachers and students in higher education $[6,7,8]$. This is achieved by combining fulltime and distance learning in the context of a digital environment that requires an employee of an educational organization to apply skills and abilities - which is a prerequisite for effective learning and interaction in a new social reality, using the capabilities of the Internet, software and communication tools with students during the class [9].

The building up of an electronic informational and educational environment (EIEE) in the educational process, involving the use of online resources and telecommunication technologies, is spelled out in the Federal Law "On Education in the Russian Federation" and the Federal State Educational Standard of a new revision. In addition, the use of high-tech methods and tools in the field of education is provided for by a number of state and regional programs: "Information Society" (2011 - 2020), "Development of Education until 2025".

The large-scale study "Students of the New Millennium: Work on a Project", conducted by experts of the Organization for Economic Cooperation and Development, describes the impact of digitalization on improving communication skills, primarily in areas related to visual thinking and the corresponding perception of the surrounding reality (not related to verbal activity). Also worth mentioning is the Programme for International Teacher Assessment, which demonstrates the presence of a positive relationship between access to an information OS and the development of communicative skills: for students who have no unlimited access to such an environment the results are far from perfect, making up only $63 \%$ of the global average. Less than a third of high school students who have a very rough idea of computer technology have managed only the simplest communicative tasks that correspond to the basic level of relevant competence. In particular, the success of these exercises was affected by the lack of confidence in their sufficient ability to communicate online. In accordance with the results of the global study "Innovative Teaching and Learning", conducted on the basis of secondary and higher education, the development of communication skills occupies a key place in the context of information OS [10].

Thus, it can be argued that the formation of communicative competence as the basic property of a modern, open personality is a promising task for domestic and foreign education in the first half of the 21 st century.

The basis of the digital educational environment in the context of the application of information management technologies may be special operational systems that integrate information from related sciences [11]. Such systems are required to facilitate the unification, accumulation and preservation of knowledge, as well as ensuring free access to intellectual resources, which creates opportunities for:

1) integration of different data sources on different disciplines, areas of activity and subjects of the educational process (students and teachers) within the same system;

2) continuous improvement of the system due to the enrichment of the theoretical data base and the constant accumulation of practical experience acquired by teachers and students in the learning process;

3) selection of such information for each student that would correspond to his capabilities and needs, as well as the educational task being performed. 


\section{Analysis and methods}

Our analysis of the works of domestic and foreign authors contributed to the establishment of the following basic functions of information type technologies application during the training of future representatives of a particular profession:

1) informational and educational - obtaining new information in the field of theory and methodology, popularizing pedagogical innovations;

2) formative - aimed at sharpening methodological skills, creating models and constructs of the objects and phenomena under consideration, building the educational process as a whole and its specific components (content, teaching methods, etc.);

3) estimative and corrective - involves resorting to means of monitoring academic performance and quality of educational services, implementing applied tasks, establishing stable feedback with students and their parents using modern OS resources, etc .;

4) research - is directly related to the disclosure of the student's creative potential (simulation-reproducing and developing-training systems, approved versions of practiceoriented programs, creativity exercises).

The above functions do not act separately, but as elements of a single system, depending on the conditions determined by the features of the EIEE - such as the conditions of didactic multidimensionality, adaptability and productive interaction. A significant number of authors emphasize the existence of a pronounced conflict between two aspects: 1) an increase in the number and complication of the content of the incoming information, which has a decisive influence on the "content" of education and 2) the limited training time and mental resources of students and schoolchildren. Much attention is currently being paid to the persistent contradiction that exists between stagnation, the traditionalist nature of the educational system and the challenges that future specialists face with in a modern high-tech reality [12, $13,14]$. The experience of communication with the young generation indicates a sense of bewilderment that a traditional approaches to education cause in a student familiar with the advantages of computer technology. This is due to the mismatch between the huge potential of the digital educational environment and its illiterate use in the educational process.

The main idea, which is contained in most of the works, can be described as follows: to eliminate the difficulties and contradictions of Russian professional education, an effective scenario of building the EIEE and methods of its application in the educational process are needed. The basic differences are in the interpretation of information resources, as well as in the methods of their design and implementation in the educational process.

As a rule, researchers limit the informatization of education to the creation of adequate software and separate methods for its use in teaching schoolchildren and preparing future specialists, without touching the essence, goals, characteristics of the target audience and other basic aspects of education.

Many modern authors divide the information technologies that make up EIEE into two related, complementary categories: computer and communication. Consequently, the scientific and pedagogical community is not aimed at improving educational methods and developing "advanced" educational materials that meet the spirit of times, taking into account the specifics of their application using electronic support tools for the educational process. This worsens the already difficult, even dangerous situation in the national secondary and higher education due to the destruction of intra-subject and interdisciplinary connections.

So, the appeal to the "Genius" software package in mathematics classes is not consistent with the classical content of this discipline and the traditional approach to teaching it in specialized universities, since students do not understand why they need to solve problems on their own (and even in various ways), if the computer copes with them perfectly. At the same time, students do not see the need to master software packages for the reason that the solution of standard tasks provided for by the curriculum does not require the use of 
innovative technologies. As a result, interest in mathematical methods, software packages, and in the studied discipline as a whole, falls [15].

The analysis made it possible to identify the following main functions of using information technology in the process of training specialists in a university:

- informational and educational function - the acquisition of new scientific and methodological knowledge, the dissemination of advanced pedagogical technologies;

- formative function associated with the development of methodological skills, simulation and construction of the studied objects and phenomena, designing the learning process and its individual elements (content, form of training, etc.);

- estimative and corrective function involves the use of knowledge control tools, experttraining systems, interactive solution of practical problems, the use of tools according to the type of programmed tasks for organizing feedback, etc.;

- diagnostic function is associated with monitoring the quality of training;

- research function is directly related to the formation of the creative abilities of a future specialist (simulation-modeling systems, intellectual-training systems, integrated application software packages, creative tasks).

The listed functions do not act in isolation, but are interconnected and obey important requirements dictated by the specifics of training and education, such as the requirements of didactic multifunctionality, adaptability and interactivity.

The most effective way to implement changes in the transformation of teaching content in the new conditions is to create a kind of "conceptual map" that guides pedagogical decisions regarding the selection of material for each topic and, further, indirectly determines the form and style of presentation of the selected material to students. Why is such a concept as a map offered here? Indeed, we are accustomed to linear planning and material selection, presented in the form of a simple linear algorithm scheme. This form is dictated by the fact that earlier educational material came from one source (textbook), where there was a crosscutting ideological line, while additional materials were used to a limited extent. Today, with the active evolution of educational content using information technology, material for each topic can be selected from different sources, which requires a selection scheme that is much more complex, which today looks like a "conceptual map".

\section{Discussion and results}

The conceptual map combines a sequence of data sources for each topic of the subject, the purpose of which is not only to give students a certain average amount of knowledge, but also to reflect different opinions and positions, forming a generalized and, if possible, complete picture for students. Based on the fact that for each topic different and not matching sources located on different sites and pages can be used, this concept was called a map.

Considering its practical implementation, it is necessary to note the main thing: the conceptual map is not an unshakable monolith and it can (and in some cases it should) change almost annually, in connection with the emergence of new studies, information sources, etc. In the rest, its compilation and, naturally, the determination of the content of teaching follows from the personal professional orientation of the teacher, which reflects a set of knowledge and beliefs in the context of a certain epistemology and subject subculture with traditions and predecessors [16]. Here, on the one hand, a certain subjectivity is revealed, within which almost all subject teachers, representatives of one generation, with rare exceptions, work in approximately the same paradigm, at the same time, having great potential for individual variations in practice. There is another important feature of the pedagogical community resistance to imposed new principles and approaches, both in relation to the content of the subject, and how to convey it to students. Research in practical subject areas has shown that 
teachers and educators tend to apply new materials and methods only if these innovations are consistent with their epistemological beliefs and personal professional worldview.

Thus, teachers with a more constructive orientation are more open to the implementation of information and communication technologies (ICT) and, moreover, tend to choose open source software that has a large number of practical possibilities. Advocates of transmission pedagogy, in turn, are inclined towards limited integration when ICTs are applied to a limited extent, rather as a tool for implementing individual functions or solving specific narrow problems, such as illustration and visualization. In the second case, naturally, we will not discuss the formation of a full-scale conceptual map of the selection and updating of educational content in the subject, but the introduction of its elements. Identically, the selection and maintenance of content is influenced by the epistemological orientation of teachers. In practice, it should be borne in mind that epistemology has several objective types, adherence to which will determine the selection of material and, as a consequence, the style of its presentation. Among them: empiricism; idealism; rationalism; constructivism; pragmatism and skepticism.

The integration of ICTs in the process of intellectual development of students as part of the educational process and the goal of the teacher's professional and pedagogical activity can be implemented in three general directions - from top to bottom, from bottom to top and horizontally $[17,18]$.

According to the first type, the teacher or some other expert acts as the only source of knowledge for the student, and students act as acceptors of ready-made knowledge transferred to them in an a priori organized educational process.

According to the second model, the student or group has to independently find the sources of knowledge and, as a result, organize the learning and development process independently in their own understanding and responsibility for the results.

However, the third form is the most common - horizontal. It involves joint activities for the purposeful development and provision of conditions for self-development of students' intellect, where all interested actors - teachers, students themselves, invited experts, classmates and parents - fulfill their purpose. Here, ICT is used to organize intensive information exchange and form a special educational-informational-intellectual environment, getting into which the student develops his intellect and acquires certain, albeit rudimentary, competencies, even possibly not wanting to himself. The center of this environment, its generator and moderator, should objectively be a teacher [19].

Considering the approaches to the practical implementation of this model, it should be noted that among the largest specific features of this process the confrontation and the clash of two paradigms that often determines the practice of transformations come to the fore: the clash of teaching using ICTs with teaching about ICTs. Often, the introduction of ICT in the educational process and professional and pedagogical activity is only a declaration, and their real use is replaced by stories about the opportunities that they provide [20]. Therefore, the situation continues when students, by the degree of integration of ICT into their lives and individual educational activities are far ahead of teachers.

At the same time, it should be noted that the formal integration of ICT in teaching is also clearly not enough. To obtain the necessary positive results, the teacher must carefully plan the implementation of ICT in such a way that he takes into account not only the specifics of mastering information technologies by himself, its application for the development of a particular educational material, but also the various levels of existing and emerging competencies of students in the field of ICT. The lack of an even accounting for these factors can create a discrepancy between the level at which the student can use ICT and the extent to which their use is supposed by the teacher to master this material. 


\section{Conclusion}

The analysis allows the authors to argue that at this stage of educational process evolution, the main task is to create a methodology related to the use of information management technologies in the development of educational electronic materials and their implementation in the context of educational activities.

The digital educational environment of the university is defined by us as the infrastructure of pedagogical activity, which favors the development of personality in the context of education and consists of three substructures (information, material and technical, educational) that aim teachers and students to achieve high learning outcomes. The innovative educational environment as an integrated, multidimensional system of information and communication technologies combines the informational component of the educational process with the pedagogical one, and increases the level of competence of teachers and students.

\section{References}

1. E.V. Smirnova, A.A. Dobrjkov, A.P. Karpenko \& V.V. Syuzev, Mentally structured educational technology and engineers preparation quality management, Communications in Computer and Information Science, 754, pp. 119-132 (2017). Retrieved from www.scopus.com

2. M.F. Alcibar, A. Monroy \& M. Jiménez, Impact and use of information and communication technologies in higher education, Informacion Tecnologica, 29(5), 101110 (2018). Retrieved from www.scopus.com

3. D.V. Drobyshev, K.A. Neusypin \& T.Yu. Tsibizova, Distance education in the training system of highly qualified personnel, AIP Conference Proceedings 2195, 020066 (2019); https://doi.org/10.1063/1.5140166. Retrieved from www.scopus.com

4. P. Svoboda, Digital technology as a significant support for the teaching process, Intelligent Systems and Computing, 1018, pp. 383-389 (2020). Retrieved from www.scopus.com

5. M.G. Sergeeva, Y.A. Chighovskaya-Nazarova, S. V. Dmitrichenkova, S. Y. Papirovskaya, V. A. Chauzova \& I. S. Andryushchenko, Effectiveness verification of the application of imitation methods of education in the training of a specialist, Espacios, 39(38), pp. 11 (2018). Retrieved from www.scopus.com

6. V.V. Nikitina \& E.V. Chernega, Personal interests transformation in students of ITspecialties during educational process at the university, Perspektivy Nauki i Obrazovania, Vol. 34, I. 4, pp. 78-83 (2018). Retrieved from www.scopus.com

7. S.N. Sailin \& N.A. Mahmor, Improving student teachers' digital pedagogy through meaningful learning activities, Malaysian Journal of Learning and Instruction, 15(2), pp. 143-173 (2018). Retrieved from www.scopus.com

8. S. Arunkumar, S. Sasikala \& K. Kavitha, Towards enhancing engineering education through innovative practices in teaching learning, International Journal of Engineering and Advanced Technology, 8, pp. 153-159 (2018). Retrieved from www.scopus.com

9. T.Yu. Tsibizova, V.M. Postnikov \& S.B. Spiridonov, Analysis of the impact of technology lectures-visualizations on the results of control measures in various academic disciplines, Perspektivy Nauki I Obrazovania, 33(3), pp. 358-363 (2018). Retrieved from www.scopus.com

10. M.G. Sergeeva, L.N. Latipova, I.V. Rekhtina, N.I. Sannikova, D.N. Zemliakov \& L.A. Shvedov, Organization of monitoring in the quality management system of the 
educational process when training of specialists, Humanities and Social Sciences Reviews, 7(6), pp. 227-232 (2019). Retrieved from www.scopus.com

11. A.P. Sukhodimtseva, M.G. Sergeeva, M.V. Donskaya, M.E. Kupriyanova \& S.B. Tomashevich, Metadisciplinarity in education: Solving actual problems, Espacios, 39(2), p. 27 (2018). Retrieved from www.scopus.com

12. A.A. Gibb, Exploring the synergistic potential in entrepreneurial university development: Towards the building of a strategic framework, Annals of Innovation \& Entrepreneurship, 3, pp. 1-24 (2012). Retrieved from www.scopus.com

13. A.A. Aleksandrov, Fang Ke, A.V. Proletarsky \& K.A. Neusypin, Conception complex continuous education with innovative information technologies, Proceedings of 2 nd International Conference on Education and Education Management (EEM 2012), pp. 374-378 (2012). Retrieved from www.scopus.com

14. A.A. Larionova, N.A. Zaitseva, Y.F. Anoshina, L.V. Gaidarenko \& V.M. Ostroukhov, The modern paradigm of transforming the vocational education system, Astra Salvensis, 6, pp. 436-448 (2018). Retrieved from www.scopus.com

15. Y.I. Dimitrienko, E.A. Gubareva, Neural network model of mathematical knowledge and development of information and educational environment for mathematical training of engineers, Journal of Physics: Conference Series, 1141(1),012010 (2018). Retrieved from www.scopus.com

16. M.G. Sergeeva, L.N. Kodaneva, A.E. Islamov, E.S. Kornakova, A.V. Serebrennikova, I. V. Panko \& T. V. Avdeeva, The development of teachers pedagogical competence in the conditions of professional educational organization, Humanities and Social Sciences Reviews, 7(4), pp. 827-832 (2019). Retrieved from www.scopus.com

17. I. Kmecová, Digitization, Digital Technology, and Importance of Digital Technology in Teaching, Lecture Notes in Networks and Systems, 84, pp. 526-537. Retrieved from www.scopus.com

18. Q. Jian, Effects of digital flipped classroom teaching method integrated cooperative learning model on learning motivation and outcome, Electronic Library, 37(5), pp. 842859 (2019). Retrieved from www.scopus.com

19. T. Nousiainen, M. Kangas, J. Rikala \& M. Vesisenaho, Teacher competencies in gamebased pedagogy, Teaching and Teacher Education, 74, pp. 85-97 (2018). Retrieved from www.scopus.com

20. A.S. Burlea \& D.D. Burdescu, An integrative approach of E-learning: From consumer to prosumer, Smart Innovation, Systems and Technologies, 59, pp. 269-279 (2016). Retrieved from www.scopus.com 